\title{
Update on the use of magnesium sulphate for fetal neuroprotection in preterm birth
}

\author{
César Hernán Meller, M.D., ${ }^{a}$ Gustavo Izbizky, M.D., ${ }^{a}$ and Lucas Otaño, M.D. ${ }^{a}$
}

\begin{abstract}
The administration of magnesium sulphate to mothers at risk for preterm birth for fetal neuroprotection has demonstrated to reduce the risk of cerebral palsy and gross motor dysfunction by $30-40 \%$. Although there is controversy regarding the regimen of administration of magnesium sulphate, the gestational age limit, the extent of its potential benefit or even if it provides any benefit, current evidence is enough to support the use of magnesium sulphate in women at imminent risk for preterm delivery before 32 weeks of gestation. The objective of this study is to describe available evidence and current recommendations regarding neuroprotection with magnesium sulphate.

Key words: magnesium sulphate, preterm birth, cerebral palsy, neuroprotective agents, pregnancy.
\end{abstract}

http:/ / dx.doi.org/10.5546/aap.2015.eng.345

\section{INTRODUCTION}

Cerebral palsy is the most common cause of motor disability during childhood. ${ }^{1}$ The International Executive Committee for the Definition of Cerebral Palsy proposed the following definition: "A group of lifelong disorders of the development of movement and posture, causing activity limitations that are attributed to non-progressive disturbances that occurred in the developing fetal or infant brain. Motor disorders of cerebral palsy are often accompanied by disturbances of sensation, perception, cognition, communication and behavior, by epilepsy and by secondary musculoskeletal problems." ${ }^{2}$

The prevalence of cerebral palsy is approximately 2-4/1000 live births $s^{1,3}$ and its main risk factors include prematurity and multiple pregnancy. The incidence of prematurity is increasing; for example in the United States, it increased $36 \%$ between 1981 and 2008, and in Denmark it rose 22\% between 1995 and $2004 .{ }^{4}$

In turn, the risk of cerebral palsy decreases with increasing gestational age: $14.6 \%$ at $22-27$ weeks of gestation, $6.2 \%$ at $28-31$ weeks, $0.7 \%$ at $32-36$ weeks, and $0.1 \%$ in term infants. ${ }^{5}$

However, more than $50 \%$ of cases of cerebral palsy occur in term infants since most births take place in this group. Similarly, the prevalence of multiple pregnancy has increased steadily from 1980 to 2009 (from 18.9 to 33.2 per 1000 births). ${ }^{7}$

Considering the importance of these risk factors, their strong interrelation, and the possibility of implementing an intervention in this group of patients, it is critical to design effective strategies that will have an impact in terms of reducing the rate of cerebral palsy. ${ }^{6}$ Below, we will analyze available evidence and recommendations regarding neuroprotection with magnesium sulphate.

\section{SOURCE OF THE HYPOTHESIS ON MAGNESIUM SULPHATE FOR NEUROPROTECTION}

In 1995, Nelson and Grether demonstrated that preterm infants with a birth weight of less than 1500 grams, exposed in utero to magnesium sulphate (as prevention of eclamptic seizures or as a tocolytic agent) had lower rates of cerebral palsy, with a reduction in the average risk over $80 \%$ (odds ratio [OR]: $0.14,95 \%$ confidence interval [CI]: $0.05-0.51){ }^{8}$ This and other similar observations triggered the conduction of randomized clinical trials with the specific purpose of assessing the role of magnesium sulphate for neuroprotection. Their findings and subsequent meta-analyses showed that the administration of magnesium sulphate to mothers at risk of imminent preterm birth (before 30-32 weeks) significantly reduced the risk of cerebral palsy. 


\section{BENEFITS OF MAGNESIUM SULPHATE}

A systematic review and meta-analysis by the Cochrane Collaboration ${ }^{9}$ on the use of magnesium sulphate for fetal neuroprotection included five studies with 6145 children. ${ }^{10}$ These studies were heterogeneous in terms of inclusion criteria (risk of preterm birth, preterm premature rupture of membranes, preeclampsia), gestational age at the time of recruiting, and dose regimens (Table 1).

Main findings were as follows:

- Pediatric mortality: There were no significant differences between children exposed to magnesium sulphate and those not exposed: RR: 1.04 (95\% CI: 0.82-1.17).

- Cerebral palsy: The administration of antenatal magnesium sulphate showed a 32\% relative reduction of cerebral palsy: RR: 0.68 (95\% CI: 0.54-0.87). The number needed to treat to prevent a case of cerebral palsy was 63 (95\% CI: 39-172).

- Gross motor dysfunction: This also showed a significant reduction: RR: 0.61 (95\% CI: 0.440.85).

Currently available evidence indicates that magnesium sulphate as neuroprotection may have a beneficial effect by reducing the risk of cerebral palsy and long-term gross motor dysfunction by $30-40 \%$. In addition, the 6-year follow-up of the ACTOMgSO 4 (Australasian Collaborative. Trial of Magnesium Sulphate) cohort study was recently published, ${ }^{11}$ which is the longest-term follow-up reported to date. ${ }^{12}$ The follow-up did not show differences in terms of neurology, cognition, behavior, growth or performance in the school-aged population who received magnesium sulphate for neuroprotection and those who did not. Similar findings were observed in the long-term follow-up of the French study PREMAG (Magnesium sulphate given before very-preterm birth to protect infant brain). ${ }^{13}$ However, it is still unknown whether the lack of a long-term benefit may be due to incomplete follow-up of patients, which reduces study power, or because cognitive development is influenced by many environmental factors that cannot be measured. ${ }^{14}$ It is also worth noting that none of these two studies found evidence of damage in the long-term follow-up, suggesting that the beneficial effects at two years are not constrained by subsequent damaging effects. ${ }^{14}$ Notwithstanding this, more studies are required to reach an adequate sample size.

\section{NEUROPROTECTIVE MECHANISMS OF ACTION}

It is believed that cerebral palsy is the result of a neuronal injury secondary to inflammation, hypoxia, excitement and/or free radical oxidation. ${ }^{1}$ Although the exact mechanism by which magnesium sulphate acts as protector of the developing brain is still unknown, different theories have been proposed: ${ }^{1}$

- Hemodynamic stability.

- Prevention of excitement injuries and neuronal stabilization.

- Antioxidant properties.

- Anti-inflammatory properties.

TABLE 1. Studies included in the Cochrane review with inclusion criteria and magnesium sulphate regimens

\begin{tabular}{|c|c|c|c|}
\hline Study & GA upon entry (weeks) & Intention-to-treat & Magnesium sulphate regimen \\
\hline Mittendorf, $2002^{26}$ & $25-33$ & $\begin{array}{c}\text { Tocolysis }(<4 \mathrm{~cm} \text { of cervical dilation }) \\
\text { vs. other tocolytic agent } \\
\text { Neuroprotection of the fetus / child }(>4 \mathrm{~cm}) \\
\text { vs. placebo }\end{array}$ & $\begin{array}{c}4 \mathrm{~g} \text { bolus + maintenance } \\
\text { with } 2-3 \mathrm{~g} / \mathrm{h} \\
4 \mathrm{~g} \text { bolus (no repetition) }\end{array}$ \\
\hline Rouse, $2008^{22}$ & 24-32 & $\begin{array}{l}\text { Neuroprotection of the fetus/child } \\
\text { vs. placebo }\end{array}$ & $\begin{array}{l}6 \mathrm{~g} \text { bolus over } 20-30 \mathrm{~min}+ \\
\text { maintenance with } 2 \mathrm{~g} / \mathrm{h}\end{array}$ \\
\hline Crowther, $2003^{11}$ & $<30$ & $\begin{array}{l}\text { Neuroprotection of the fetus/child } \\
\text { vs. placebo }\end{array}$ & $\begin{array}{l}4 \mathrm{~g} \text { bolus over } 20 \mathrm{~min}+ \\
\text { maintenance with } 1 \mathrm{~g} / \mathrm{h} \\
\text { up to } 24 \mathrm{~h} \text { or delivery }\end{array}$ \\
\hline Marret, $2008^{27}$ & $<33$ & $\begin{array}{l}\text { Neuroprotection of the fetus/child } \\
\text { vs. placebo }\end{array}$ & $4 \mathrm{~g}$ bolus \\
\hline $\begin{array}{l}\text { Magpie Trial } \\
\text { Collaborative Group, } \\
2002^{28}\end{array}$ & $<37$ & $\begin{array}{l}\text { Neuroprotection of the preeclamptic mother } \\
\text { vs. placebo }\end{array}$ & $\begin{array}{l}4 \mathrm{~g} \text { bolus over } 10 / 15 \mathrm{~min}+ \\
\text { maintenance with } 1 \mathrm{~g} / \mathrm{h} \text { up to } 24 \mathrm{~h} \\
\text { or with } 5 \mathrm{~g} / 4 \mathrm{~h} \mathrm{IM} \mathrm{up} \mathrm{to} 24 \mathrm{~h}\end{array}$ \\
\hline
\end{tabular}




\section{INDICATIONS OF MAGNESIUM SULPHATE FOR NEUROPROTECTION}

Magnesium sulphate for neuroprotection is indicated in the case of imminent preterm birth, both in single and multiple pregnancies before 32 weeks. In this setting, an imminent birth is defined as a high probability of giving birth due to the presence of labour with cervical dilation $>4 \mathrm{~cm}$, with or without premature rupture of membranes, or a scheduled preterm birth for maternal or fetal indications. ${ }^{5,15}$

Given the heterogeneity of published studies (Table 1), there is no consensus in relation to the gestational age limit for the indication of magnesium sulphate, and for this reason different countries have different protocols. This is evident in the range of published guidelines. The guidelines of the Binational Clinical Practice of Australia and New Zeland ${ }^{16}$ and the Royal College of Obstetricians and Gynaecologists ${ }^{5}$ establish 30 weeks as a limit, while the guidelines of the Society of Obstetricians and Gynaecologists of Canada,${ }^{17}$ the Society of Maternal-Fetal Medicine of the United States, ${ }^{17}$ and the Recommendations for managing pregnancy and newborn infants in the limits of viability of the Ministry of Health of Argentina recommend a 32-week limit. ${ }^{15}$

A recent Canadian study ${ }^{18}$ also demonstrated that the administration of magnesium sulphate at $<32$ weeks to pregnant women at risk of imminent birth might be a cost-effective strategy, since it estimates that each prevented case of cerebral palsy saves approximately 1.5 million dollars.

There is controversy concerning the costeffectiveness of this strategy at later gestational ages, since the risk of cerebral palsy decreases as gestational age increases and, as a result, the number of women needed to treat to prevent a case of cerebral palsy also increases. Besides, most studies were conducted in pregnancies before 33 weeks of gestation (Table 1).

\section{Up to 34 weeks?}

Although neuroprotection in Australia is indicated up to 30 weeks, at present there is an ongoing randomized, multicenter study called MAGENTA (Magnesium sulphate at 30 to 34 weeks' gestational Age: Neuroprotection Trial) led by the University of Adelaide, that will compare the administration of magnesium sulphate between 30 and 34 weeks versus placebo. ${ }^{19}$ The primary hypothesis is that magnesium sulphate administered to patients at risk of imminent preterm birth at this gestational age reduces mortality or cerebral palsy rates at two years of adjusted age.

\section{After 37 weeks?}

More than $50 \%$ of cerebral palsy cases occur in the group of term infants. ${ }^{6,20}$ For this reason, one question that arises is whether magnesium sulphate may play a neuroprotective role in term pregnancies with increased risk of cerebral palsy, for example, due to intrauterine growth restriction or chorioamnionitis.

A recent Cochrane review ${ }^{6}$ analyzed randomized studies comparing the use of magnesium sulphate in term pregnancies versus placebo (a study on 135 patients with mild preeclampsia), and found no significant differences in the Apgar score at 5 minutes or gestational age at the time of birth, serious adverse events leading to treatment discontinuation, or the rates of postpartum hemorrhage and C-section.

Authors concluded that evidence is not yet enough to assess the safety and effectiveness of magnesium sulphate for fetal neuroprotection in term pregnancies and that further research is required. In short, at present there is no evidence to support the use of magnesium sulphate for neuroprotection in term pregnancies.

\section{CONTRAINDICATIONS OFMAGNESIUM SULPHATE FOR NEUROPROTECTION}

Contraindications of this drug for neuroprotection are similar to those for the prevention of eclampsia: hypersensitivity to magnesium sulphate, myasthenia gravis, severe liver disease, and fetal malformations or genetic anomalies less likely to benefit. In the case of kidney failure, the dose should be reduced and magnesium levels should be monitored.

\section{Regimen of administration}

Schedules for the administration of magnesium sulphate for neuroprotection vary from one study to the other (Table 1). All include a loading dose of 4-6 $\mathrm{g}$, but not all include a maintenance dose. In those that do, the dose ranges from $1 \mathrm{~g} / \mathrm{h}$ to 3 $\mathrm{g} / \mathrm{h}$. The scheme recommended by the Ministry of Health of Argentina is as follows: ${ }^{15}$

Loading dose: $4 \mathrm{~g}$ IV over 30 minutes (4 vials of $5 \mathrm{~mL}$ of $25 \%$ solution in $100 \mathrm{~cm}$ of $5 \%$ dextrose).

Maintenance dose: $1 \mathrm{~g} / \mathrm{h} \mathrm{IV} \mathrm{(10} \mathrm{vials} \mathrm{in} 500 \mathrm{~mL}$ of $5 \%$ dextrose to $40 \mathrm{~mL} / \mathrm{h}$ using a pump).

Magnesium sulphate should be discontinued once birth takes place, when it is no longer 
imminent, or after 24 hours from dose initiation. ${ }^{15}$ If therapy is discontinued and birth turns imminent again, a new course of magnesium sulphate is not recommended. ${ }^{15}$

For scheduled preterm births (for example, severe intrauterine growth restriction, severe preeclampsia), magnesium sulphate infusion should be administered ideally at least 4 hours before birth. ${ }^{15}$ A recent secondary analysis ${ }^{21}$ of a randomized multicenter study ${ }^{22}$ assessed the association between the duration of magnesium sulphate infusion ( $<12 \mathrm{~h}, 12$ to $18 \mathrm{~h}$, and $>18 \mathrm{~h}$ ) and adverse perinatal outcomes, such as fetal and neonatal death, and cerebral palsy, and found no significant differences; therefore, the optimal duration of exposure to this agent is still unknown. ${ }^{21}$

If the clinical situation calls for immediate pregnancy ending for fetal or maternal reasons, the recommendation is not to delay birth in order to complete magnesium sulphate infusion. ${ }^{15}$

\section{ADVERSE EVENTS}

These may be classified into maternal (Table 2), fetal and obstetric adverse events.

\section{Maternal adverse events}

Magnesium sulphate causes peripheral vasodilation when used intravenously. In studies conducted with magnesium sulphate indicated for neuroprotection, the most common events included blushing, sweating, and nausea and vomiting. However, maternal serious adverse events were uncommon: the only significant events included hypotension and tachycardia, and there were no maternal deaths or cardiorespiratory arrest cases in the treated group (Table 2). ${ }^{23}$

A recent randomized study conducted in Australia (Maternal adverse effects with different loading infusion rates of antenatal magnesium sulphate for preterm fetal neuroprotection: the IRI randomized trial) ${ }^{24}$ compared the rate of administration of the magnesium sulphate loading dose for neuroprotection to assess whether different regimens may reduce the rate of maternal adverse events. Pregnant women were randomized to a $4 \mathrm{~g}$ magnesium sulphate loading dose over 20 minutes or over 60 minutes, followed by a maintenance dose. The overall rate of adverse events was $71 \%$ in the first hour, with no differences among the groups except for a lower number of heat and redness episodes at 20 minutes in the slow infusion group (RR: $0.49,95 \%$ CI: 0.24-0.99). There were no other differences, including treatment discontinuation due to an adverse event. In short, it seems that the infusion rate of the loading dose should not be modified; it is necessary to study other strategies to reduce the rate of maternal adverse events.

\section{Fetal adverse events}

Prolonged use of magnesium sulphate $(>48 \mathrm{~h})$ is contraindicated due to the risk of bone anomalies and calcium, phosphorus and magnesium alterations in fetuses and newborn infants. ${ }^{20,25}$

For this reason, the Food and Drug Administration (FDA) modified the pregnancy

TABLE 2. Maternal outcomes observed in studies using magnesium sulphate for neuroprotection

\begin{tabular}{lccc}
\hline Maternal side effects/adverse events & $\begin{array}{c}\text { Magnesium sulphate } \\
\mathbf{n}(\mathbf{\%})\end{array}$ & $\begin{array}{c}\text { Placebo } \\
\mathbf{n ~ ( \% )}\end{array}$ & $\begin{array}{c}\text { RR } \\
\mathbf{( 9 5 \% ~ C I ) ~}\end{array}$ \\
\hline Any & $1356 / 1917(70.7)$ & $343 / 1950(17.6)$ & $5.05(2.06-12.39)$ \\
\hline Mild effects & & & \\
$\quad$ Blushing & $1119 / 1917(58.4)$ & $614 / 1631(37.6)$ & $411 / 1631(25.2)$ \\
Injection site discomfort & $312 / 1917(16.3)$ & $162 / 1950(8.3)$ & $68 / 1672(4.1)$ \\
Sweating & $57 / 1672(3.4)$ & $76 / 1950(3.9)$ & $7.56(3.39-16.88)$ \\
Nausea and vomiting & $9.12(7.19-11.57)$ & $6.37(1.96-20.68)$ & $4.60(1.54-13.75)$ \\
\hline Serious events & & & $41 / 1631(2.5)$ \\
Hypotension & $80 / 821(9.7)$ & $56 / 535(10.5)$ & $0 / 1917$ \\
Tachycardia & $8 / 1096(0.7)$ & $123 / 1631(7.5)$ & $36 / 527(6.8)$ \\
Respiratory depression & $0 / 1917$ & $52 / 805(6.5)$ & $44 / 1672(2.6)$ \\
Lung edema & $31 / 1672(1.9)$ & $3 / 1145(0.3)$ & $1.51(1.09-2.09)$ \\
Infusion discontinuation due to side effects & $1 / 1950$ & $0 / 1950$ & $2.79(0.74-10.47)$ \\
Death & $1.53(1.03-2.29)$ & $1.31(0.83-2.07)$ & - \\
Cardiac or respiratory arrest & $2.81(2.01-3.93)$ & $0.32(0.01-7.92)$ & \\
\hline
\end{tabular}

RR: relative risk.

Adapted from Conde-Agudelo and Romero, 2009. 
category from "A" (adequate studies have failed to demonstrate a risk to the fetus) to " $D$ " (although there is fetal risk, its use may be accepted if potential benefits outweigh potential risks). ${ }^{20}$ The evidence leading to this modification was obtained from studies with serious methodological limitations so as to compare it with the use of magnesium sulphate for neuroprotection. The mean exposure to magnesium sulphate in the 18 reports of bone demineralization and fractures in fetuses and newborn infants was 9.6 weeks (67 times the exposure for neuroprotection), with a mean overall maternal dose of $3700 \mathrm{~g}$ (157 times the recommended dose in obstetrics). ${ }^{25}$

Magnesium sulphate has been used in obstetrics probably since the 1920s, with different indications (eclampsia prevention, tocolysis), decades of drug surveillance, and more than 15000 women enrolled and followed in different randomized studies, but none reported concerns in terms of fractures or demineralization. Therefore, with the recommended doses for some of its obstetric uses, including neuroprotection, bone changes are not expected to be a concern; the FDA's recategorization is based on non-standard uses not indicated for this drug. ${ }^{25}$

In addition, randomized studies using magnesium sulphate for neuroprotection did not affect the incidence of the Apgar score $<7$ at 5 minutes (RR: 1.03, 95\% CI: 0.9-1.18, three studies, 4387 newborn infants), neonatal hypotonia (RR: 1.02, 95\% CI: 0.77-1.36, one study, 2444 newborn infants) or mechanical ventilation requirement (RR: 0.94, 95\% CI: 0.89-1.00; three studies, 4387 newborn infants). ${ }^{3}$ In turn, a subanalysis of the BEAM study (Beneficial Effects of Antenatal Magnesium Sulphate Trial) found no correlation between the magnesium level in umbilical cord blood and the requirement of ventilation, intubation or chest compressions. ${ }^{3}$ In addition, there were no differences in terms of seizures, respiratory distress syndrome, bronchopulmonary dysplasia or necrotizing enterocolitis. ${ }^{3}$

\section{Maternal adverse events}

In a meta-analysis of magnesium sulphate for neuroprotection, Conde-Agudelo and Romero ${ }^{23}$ found no association with an increased rate of C-sections (42.9\% vs. $42.8 \%$, RR: 1.0, 95\% CI: 0.9 1.1 ) or severe postpartum hemorrhage (3.4\% vs. $263.2 \%$, RR: $1.1,95 \%$ CI: 0.6-1.8) when comparing the sulphate and placebo groups.

\section{MATERNAL HEALTH MONITORING}

Although magnesium sulphate is commonly used in obstetrics, it requires special precautions, which include recording maternal blood pressure, heart rate, respiratory rate, deep tendon (patellar) reflexes, and voiding. Magnesemia monitoring is not routinely indicated; only patients with renal impairment should be monitored. ${ }^{3}$ Maternal adverse events are dose-dependent, and cardiorespiratory arrest occurs only if magnesemia reaches a level that will not be reached if drug indications and contraindications are complied with.

In case of severe adverse events, one $10 \mathrm{mg}$ ampoule of calcium gluconate should be readily available for slow IV bolus administration.

\section{CONCLUSION}

Magnesium sulphate for neuroprotection in case of imminent preterm birth before 32 weeks may reduce the risk of cerebral palsy and shortterm gross motor dysfunction by $30-40 \%$.

Although there is still controversy regarding its mechanism of action, regimen of administration, gestational age limit for indication, extent of the benefit provided, and even if there is a long-term benefit, for the time being evidence seems to be enough to use magnesium sulphate for managing patients at risk of imminent preterm birth.

First of all, it seems to be effective no matter what the cause of preterm birth is. It is worth mentioning that patients with preterm labor and premature rupture of membranes were prevalent in these studies, and similar results were obtained for both categories. Secondly, unlike corticosteroids, which should be administered at least $24 \mathrm{~h}$ before birth in order to obtain a maximum beneficial effect, the window of opportunity for the administration of magnesium sulphate is shorter. In addition, obstetricians are already accustomed to using this drug since it involves the same regimen of administration used in patients at risk of eclampsia.

The impact of this strategy, neuroprotection with magnesium sulphate, will depend on adherence to and compliance with this intervention on part of the perinatal care staff at the hospital level, including obstetricians, neonatologists, midwives and nurses, similarly to what has occurred with the administration of corticosteroids to the mother. At present, any neonatologist attending a preterm infant under 32 weeks would corroborate that the mother has received corticosteroids. Likewise, commitment 
with neuroprotection will also result in a higher rate of implementation of this intervention.

\section{REFERENCES}

1. Costantine MM, Drever N. Antenatal Exposure to Magnesium Sulfate and Neuroprotection in Preterm Infants. Obstet Gynecol Clin N Am 2011;38(2):351-66.

2. Rosenbaum P, Paneth N, Leviton A, Goldstein M, et al. A report: the definition and classification of cerebral palsy April 2006. Dev Med Child Neurol Suppl 2007;109:8-14.

3. Magee L, Sawchuck D, Synnes A, von Dadelszen P. SOGC Clinical Practice Guideline. Magnesium sulphate for fetal neuroprotection. J Obstet Gynaecol Can 2011;33(5):516-29.

4. Lisonkova S, Sabr Y, Butler B, Joseph K. International comparisons of preterm birth: higher rates of late preterm birth are associated with lower rates of stillbirth and neonatal death. BJOG 2012;119(13):1630-9.

5. Royal College of Obstetricians \& Gynaecologists. Magnesium sulphate to prevent cerebral palsy following preterm birth. RCOG Scientific Impact Paper 29, 2011. [Available at: https://www.rcog.org.uk/globalassets / documents/guidelines/scientific-impact-papers/sip_29. pdf]. [Accessed on: February 19, 2015].

6. Nguyen TM, Crowther CA, Wilkinson D, Bain E. Magnesium sulphate for women at term for neuroprotection of the fetus. Cochrane Database Syst Rev 2013;28;2:CD009395.

7. Martin JA, Hamilton BE, Osterman MJK. Three decades of twin births in the United States, 1980-2009. NCHS Data Brief 2012;(80):1-8.

8. Nelson KB, Grether JK. Can magnesium sulfate reduce the risk of cerebral palsy in very low birth weight infants? Pediatrics 1995;95(2):263-9.

9. Doyle LW, Crowther CA, Middleton P, Marret S, Rouse D. Magnesium sulphate for women at risk of preterm birth for neuroprotection of the fetus. Cochrane Database Syst Rev 2009;(1):CD004661.

10. The AMICABLE Group. Antenatal magnesium individual participant data international collaboration: assessing the benefits for babies using the best level of evidence (AMICABLE). Syst Rev 2012;1:21.

11. Crowther CA, Hiller JE, Doyle LW, Haslam RR. Effect of magnesium sulfate given for neuroprotection before preterm birth-a randomized controlled trial. JAMA 2003;290(20):2669-76.

12. Doyle LW, Anderson PJ, Haslam R, Lee KJ, et al. Schoolage outcomes of very preterm infants after antenatal treatment with magnesium sulfate vs placebo. JAMA 2014;312(11):1105-13.

13. Chollat C, Enser M, Houivet E, Provost D, et al. Schoolage outcomes following a randomized controlled trial of magnesium sulfate for neuroprotection of preterm infants. J Pediatr 2014;165(2):398-400.e3.

14. Marret S, Bénichou J. Antenatal magnesium sulfate and outcomes for school-aged children. JAMA 2015;313(3):306.

15. Argentina. Ministerio de Salud. Recomendaciones para el manejo del embarazo y el recién nacido en los límites de la viabilidad. Dirección Nacional de Maternidad e Infancia,
Buenos Aires, 2014. Available at: http: / www.msal.gov.ar/ images/stories/bes/graficos/0000000513cnt-viabilidad. pdf. [Accessed on: February 19, 2015].

16. Antenatal Magnesium Sulphate for Neuroprotection Guideline Development Panel. Antenatal magnesium sulphate prior to preterm birth for neuroprotection of the fetus, infant and child: National clinical practice guidelines. Adelaide: The University of Adelaide, 2010. Available at: http://www.adelaide.edu.au/arch/ antenatalMagnesiumSulphateGuidlines.pdf. [Accessed on: February 19, 2015].

17. American College of Obstetricians and Gynecologists Committee on Obstetric Practice; Society for MaternalFetal Medicine. Committee Opinion No. 455: Magnesium sulfate before anticipated preterm birth for neuroprotection. Obstet Gynecol 2010 Mar;115(3):669-71.

18. Bickford C, Magee LA, Mitton C,Kruse M, et al. Magnesium sulphate for fetal neuroprotection: a cost-effectiveness analysis. BMC Health Serv Res 2013,13:527.

19. Crowther CA, Middleton PF, Wilkinson D, Ashwood P, et al. Magnesium sulphate at 30 to 34 weeks' gestational age: neuroprotection trial (MAGENTA)--study protocol. BMC Pregnancy Childbirth 2013;13:91.

20. Salmeen KE, Jelin AC, Thiet MP. Perinatal neuroprotection. F1000Prime Rep 2014;6:6.

21. McPherson JA, Rouse DJ, Grobman WA, Palatnik A, Stamilio DM. Association of duration of neuroprotective magnesium sulfate infusion with neonatal and maternal outcomes. Obstet Gynecol 2014;124(4):749-55.

22. Rouse DJ, Hirtz DG, Thom EA, Varner MW, et al. A Randomized trial of magnesium sulfate for the prevention of cerebral palsy. New Engl J Med 2008;359(9):895-905.

23. Conde-Agudelo A, Romero R. Antenatal magnesium sulfate for the prevention of cerebral palsy in preterm infants less than 34 weeks' gestation: a systematic review and metaanalysis. Am J Obstet Gynecol 2009 Jun;200(6):595-609.

24. Bain ES, Middleton PF, Yelland LN, Ashwood PJ, Crowther CA. Maternal adverse effects with different loading infusion rates of antenatal magnesium sulphate for preterm fetal neuroprotection: the IRIS randomised trial. BJOG 2014;121(5):595-603.

25. American College of Obstetricians and Gynecologists Committee on Obstetric Practice Society for Maternal-Fetal Medicine. Committee Opinion No 573: Magnesium sulfate use in obstetrics. Obstet Gynecol 2013;122(3):727-8.

26. Mittendorf R, Dambrosia J, Pryde PG, Lee KS, et al. Association between the use of antenatal magnesium sulfate in preterm labor and adverse health outcomes in infants. Am J Obstet Gynecol 2002;186(6):1111-8.

27. Marret S, Marpeau L, Bénichou J. Benefit of magnesium sulfate given before very preterm birth to protect infant brain. Pediatrics 2008;121(1):225-6.

28. Magpie Trial Follow-Up Study Collaborative Group. The Magpie trial: a randomised trial comparing magnesium sulphate with placebo for pre-eclampsia. Outcome for children at 18 months. BJOG 2007;114(3):289-99. 